\title{
INTERNET OF THINGS IN HIGHER EDUCATION
}

\author{
Srečko Natek, International School for Social and Business Studies, Slovenia, srecko.natek@mfdps.si \\ Dušan Lesjak, University of Primorska and International School for Social and Business Studies, Slovenia, \\ dusan.lesjak@mfdps.si
}

\begin{abstract}
There are several studies about the Internet of Things (IoT) in different areas, but just a few in the higher education area. The student-oriented higher education is traditionally still focused on face-to-face and/or online teaching and learning, mainly in the blended learning mode. The IoT platform in higher education is still in a very initial stage. Using new smart devices with a constant connection to the internet means a real difference to existing nondigital native professors and new generations of digital native students, resulting in important security and privacy issues at higher education institutions. IoT in higher education enables quick access to course videos and performs interactive responses in classrooms or anywhere, which will provide a multimedia learning environment, strengthen students' learning motivation, improve their attendance and enrich their learning experiences. The main potential of IoT is personalization of the teaching and learning process to support individual characteristics of both, professors and students, to improve the efficiency of teaching and learning. Furthermore, IoT can improve collaboration on group assignments, projects, improve student-centered approach, improve customized teaching and learning, enable smooth learning, and enable equality for diverse students and enhance their learning experience. The main purpose of this paper is to analyze and discuss the existing studies, recognize IoT main advantages and disadvantages and potential opportunities for implementing IoT applications in higher education.
\end{abstract}

Keywords: Internet of Things, IoT, higher education, higher education institutions, IoT privacy, IoT security, smart classroom, learning, teaching

\section{INTRODUCTION}

The Internet of things (IoT) has shown great potential to create a new space for development of the information industry. Literature reviews discovers broad interests, implementation and trends of developing IoT in different areas, including higher education (HE).

Higher education is traditionally still focused on face-to-face teaching or blended e-learning. The device orientation of the IoT platform in HE is still in an initial stage. Using the IoT is very different even to young students who were born in the internet era. Together with advantages, serious security and privacy issues arise at HE institutions (HEIs). The IoT in HE enables online teaching and learning activities in classrooms, campus or anywhere the students live and study. IoT can improve collaboration on student group assignments and other activities, enhance teaching and learning via personalization and specialization of various activities, based on numerous data, gathered from connected devices.

The research will focus on implementation of the IoT in HE, where the following research questions (RQ) are key to its successful implementation:

RQ1: What are the key research areas of IoT?

RQ2: What are the key research areas of IoT in HE?

RQ3: What are the key advantages and disadvantages of IoT in HE?

In the following chapters, we will focus on some existing studies to recognize the potential opportunities of implementing IoT applications in HE and explore the main future challenges to improve HE teaching and learning process. In the What is IoT and IoT trends chapter, the paper will present the latest definitions of the IoT and some IoT trends. In the chapter IoT in HE, we will observe implementing of the IoT, particularly in HE. The research will conclude with a discussion and main findings, particularly the advantages and disadvantages of the IoT in HE and conclusions.

\section{WHAT IS IoT AND IoT TRENDS?}

Ravulavaru (2018) defined the IoT as a state, where things on the Earth connect to the internet and start talking to each other. By things electronic, electrical, mechanical or electromechanical objects are meant. The IoT can be 
very helpful and very annoying at the same time. Wilkins (2019) described IoT as a series of devices with some ulterior purpose that has been given internet connectivity.

The IoT can be perceived as a far- reaching vision with technological and societal implications. From the perspective of technical standardization, the IoT can be viewed as a global infrastructure for the information society, enabling advanced services by interconnecting (physical and virtual) things, based on existing and evolving interoperable information and communication technologies. Through exploitation of identification, data capture, processing and communication capabilities, the IoT makes full use of "things" to offer services to all kinds of applications, whilst ensuring that security and privacy requirements are fulfilled. (Sibo, 2017)

The IoT platform is the support software that connects smart devices and entities that use the data from these smart devices, such as humans, other systems, etc. It is also known as IoT middleware between data collected and the user-facing application. A typical IoT platform has the following layers: smart devices, gateway, device management software, storage, API management, applications (mobile, web, dashboards), Intelligence, Rules \& Scheduling and third-party integration. Several IoT platforms are available, among them Microsoft Azure IoT, IBM Watson, Google Cloud IoT, etc. (Ravulavaru 2018).

RFID systems and wireless sensor networks are major sources of "Big Data” that organizations are starting to analyze to improve their operations and decision-making. The output from this system is fueling what is called the Industrial Internet, also known as the IoT. Software for operational intelligence and analytics enables organizations to analyze these streams of big data as they are generated in real time to trigger alerts on events or have them fed into a live dashboard for decision-making (Laudon, 2016).

The IoT is the most challenging platform that designates the correlation of physical objects in the near future (AlEmran et. al., 2019). Intense use of mobile devices connected to the internet means that the current generation of young people, who are getting higher education, has the most technological literacy ever (Moreira et. Al., 2017).

According to Sibo (2017), the function of the IoT in defining and supporting industrial development becomes conspicuous and is converted into practical productivity faster than ever. There are two driving forces of IoT development: competitive benefits in reconstructing national strategic fundamental industries with IoT technologies and aggregate to the high added-value and mass consumer market through the IoT to improve the quality of economic development and provide the impetus for development.

From a technical perspective, the IoT is made up of a growing body of sensors around the world, collecting and transmitting data. The IoT refers to the rules and events being applied to that data and makes adjustments to systems and organizations. From a conceptual standpoint, the IoT is an ability to create digital awareness of the physical world we live in. It is a digital pulse made up of data that we can aggregate to improve the world around us. From an industry and social perspective, the IoT is the basis for reinvention, much the way the internet was in the 1990s. The key technologies of most IoT solutions include sensors, connectivity, cloud storage and processing, analytics and machine learning. There are three key IoT opportunities: reinventing the customer experience (customer-centric), improving operational effectiveness and developing new business models. There are several level scenarios of using the IoT: tracking, insight and adjustment, network coordination and optimization (Rossman, 2016).

Sibo (2017) reports the following key trends: First, new spaces for economic growth stimulate innovations in technologies such as the $5 \mathrm{G}$ network, cloud computation and big data, and promote convergent innovations across industries as intelligent manufacturing. Second, Internet of Vehicles (IOV), new materials and new spaces for industrial investment promote the construction of high speed, mobile, safe and ubiquitous information infrastructures and intelligentised reconstruction of important infrastructures in energy sources and traffic. Third, new spaces for information consumption emergence of new products, such as smart wearable, smart home, and intelligent vehicles and the last new demands for information products and information services that creates new spaces for the development of the manufacturing industry.

Idnomic (2019) reports five IoT trends in 2019: edge computing, a new approach to architectures, cybersecurity; more attacks, but awareness that will pay off; automobile, autonomous driving, on-board payment and smart vehicles; artificial Intelligence and IoT, a winning combination and 5G, adapting cellular networks to the IoT. 
According to Wilkins (2019), there are no IoT safety standards. Anyone can make IoT devices without any security liability. Now cybersecurity has to evolve to "everything-security". The IoT is designed mainly with short-range Wi-Fi and radio connections.

The rise of IoT accelerates the importance of security, privacy, and infrastructure issues, especially on campus. Therefore, it is important to implement custom security protocols in higher education infrastructure such as buildings and campuses (Grama et. al. 2019).

\section{IoT IN HIGHER EDUCATION}

IoT looks like a promising technology, invented primarily for HE. Using numerous connected sensors and devices enables a higher degree of student's activities, processes and devices monitoring in HEIs and their environment. Technologically, gathered data have a potential near to total control of HE activities. For ensuring a sustained balance of HE efficient and successful processes compared to student privacy and freedom, the HEI management should obtain the right strategy for IoT implementation in everyday teaching and learning activities.

With the emergence of the IoT, human-to-human communications have been transformed into its everything-toeverything versions, e.g. human-to-human, human-to-machine and machine-to-machine communications thus capture all aspects of human life (Ramlowat et. al. 2019). Thus, Srivastava (2020) exposed the possibilities of the IoT to enhance student learning experience by educational process automation and using analytical reports and machine learning.

Mobile devices are one of the key technologies to support education and teaching (Brooks, 2020). According to Ogallo (2018), the IoT offers great potential in the realm of HE, where some principles of the IoT are already in use. IoT can enhance data-driven decision-making in the teaching and learning process in higher education. HEI can implement the policy which permits faculties, students, and administrators unrestricted access to campus networks, using their digital devices to promote and facilitate the free flow of information within higher education (Ogallo 2018).

According to Ogallo (2018), by using predictive analytics, institutions of HE can leverage the plethora of data generated from smart devices connected to campus networks to make informed decisions about institutional strategy; address campus issues through predictive and collaborative engagements; improve student completion rates and reduce costs of education. IoT applications are steadily transforming educational technologies from being static applications to more interactive tools of learning that promote experiential learning.

Wilkins (2019) described the possibilities of gathering data by IoT's ID badges with microphones, infrared transceivers and accelerometers to show student movement and speech patterns for analysing whether the ID wearer was sitting, walking, standing or running. They can furthermore analyze vocal tonality shifts to measure excitements, analyze the position of the wearer, analyze face-to-face interactions by infrared sensors, etc. Nehru (2020) further declared that adopting the IoT in education is like a new stream of change that has brought new possibilities and circumstances for the improvement of both the teaching and learning process in the education system, which is termed as Education of Things (EoT).

For 2020, Jenzabar (2020) predicted that data analysis tools can help HEIs spot trends, make accurate projections, and discover hidden opportunities for success across campus. The Association for Institutional Research (AIR), EDUCAUSE, and the National Association of College and University Business Officers (NACUBO) recently called for HEIs to invest in data and analytics, releasing a statement saying they strongly believe that using data to better understand students and operations paves the way to developing new, innovative approaches for improved student recruiting, better student outcomes, greater institutional efficiency, and cost-containment (Jenzabar, 2020).

In parallel with the rise of municipal smart cities, HE continues to push toward the smart campus, a vision of a digitally interconnected learning space in which data and devices combine to enhance the student experience. Colleges need to get smart to stay competitive (Stone 2019).

The IoT potentially brings some bad practice in HE. In the What is IoT and IoT trends chapter we already named some of them, concerning violation of students' privacy and freedom (e.g. Idnomic, 2019, Wilkins, 2019, Grama et. al. 2019). Tan (2018) realized some bad practice of using the IoT. For example, IoT devices can monitor student activities and states (e.g. sleeping, playing games, etc.), thus lowering student's motivation for activities which are 
irrelative to classroom teaching. Carefully planning how to monitor student activities and how to interpret the results is the key challenge for HEI's management. The use of Artificial Intelligence is proved to be a successful way to develop the right strategy of implementing the IoT in HE.

\section{DISCUSSION AND FINDINGS}

Numerous authors researched the IoT as one of the leading industry, home and public technologies to connect all smart devices over the internet and thus enable big data analysis of massive quantities of data to support overall control and decision making. Authors focused on a different aspect of the IoT e.g. platforms, technical viewpoint, industrial IoT, social viewpoint, safety, security, privacy and general trends of IoT, as shown for example in Table 1. Studies on IoT.

Table 1. Studies on IoT

\begin{tabular}{|c|c|c|c|c|c|c|c|}
\hline \multirow[b]{2}{*}{ Author } & \multirow[b]{2}{*}{ Keywords } & \multicolumn{6}{|c|}{ Areas } \\
\hline & & 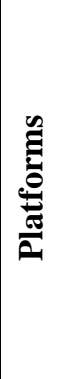 & 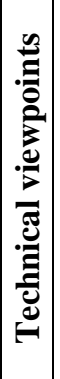 & 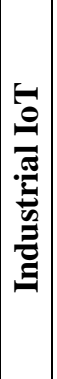 & 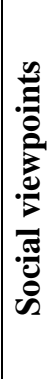 & 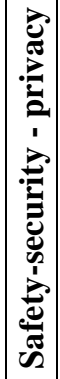 & 里 \\
\hline Laudon (2016) & $\begin{array}{l}\text { IoT*, RFID, wireless sensor network, Big Data, Industrial Internet - } \\
\text { IoT, live dashboard for decision making. }\end{array}$ & $x$ & $x$ & $x$ & & & \\
\hline Rossman (2016) & $\begin{array}{l}\text { IoT, Technical perspective of IoT, Conceptual perspective of IoT, } \\
\text { Industry perspective of IoT, Social perspective of IoT, IoT } \\
\text { solutions, IoT opportunities, scenarios of using IoT }\end{array}$ & & $\mathrm{x}$ & $\mathrm{X}$ & $\mathrm{x}$ & & \\
\hline Sibo (2017) & $\begin{array}{l}\text { IoT, IoT technological and societal implications, IoT global } \\
\text { infrastructure for information society, IoT security and privacy } \\
\text { requirements, IoT support industrial development, innovation, } \\
\text { intelligent manufacturing, information consumption. }\end{array}$ & & $\mathrm{X}$ & $\mathrm{x}$ & $\mathrm{x}$ & $\mathrm{x}$ & \\
\hline Ravulavaru (2018) & IoT, IoT platform. & $\mathrm{x}$ & & & & & \\
\hline Al-Emran (2019) & IoT, IoT platform, technological literacy. & $\mathrm{X}$ & $\mathrm{X}$ & & & & \\
\hline Idnomic (2019) & IoT, IoT trends. & $\mathrm{x}$ & & & & & $\mathrm{X}$ \\
\hline Wilkins (2019) & IoT, IoT safety standards, IoT security liability, everything-security. & & & & & $\mathrm{x}$ & \\
\hline
\end{tabular}

*We have not listed IoT in a separate column as the other keywords.

The table shows that the main research areas are IoT technical issues and corresponding platforms followed by industrial IoT, social issues and safety, security and privacy issues of IoT and authors' discussion of IoT trends. Recognized research areas are also the answer to the RQ1: What are the key research areas of IoT?

The IoT is a fast growing technology being also present in HE since it has a potential to support, enhance, improve and optimize all aspects of teaching, learning, professor and student logistic, supporting activities, infrastructure and overall HEI management. For example, the IoT could be used by HEIs to help in the teaching and learning process automation by using face and voice detection and recognition, monitoring students' cars and bikes movements, IoT devices performance analysis, biometrics for class attendance management and on-line exams, location tracking, managing the excursion - school bus, electricity management, heating and cooling, privacy and security management, student assignments and student time management, food and other supply management, etc.

According to first two columns of areas in the Table 1, the majority of authors researched technical aspects of IoT and its platforms, which prove that IoT is still rapidly evolving technology. IoT despite the fact that it is in its initial stage has already a big impact on our every day’s private and business life and a society. 
Numerous authors have also researched the IoT in HE to connect all smart devices within the HEI, Campus and all places with HE processes over the internet to enable big data analysis of gathered data to improve all aspects of HE. Authors focused on a different aspect of the IoT in HE, e.g. education of things, learning experience, digital teaching, learning space, ID badges, smart campus, infrastructure, mobile devices, trends, applications, IoT investments, policy, strategy, implementation, data-driven decision making, bad practice, safety, security, privacy, communications and competitiveness of IoT in HE, as shown in Table 2. Studies on IoT in HE.

Table 2. Studies on IoT in HE

\begin{tabular}{|c|c|c|c|c|c|c|c|c|c|c|c|c|c|c|c|c|c|}
\hline \multirow[b]{2}{*}{ Author } & \multirow[b]{2}{*}{ Keywords } & \multicolumn{16}{|c|}{ Areas } \\
\hline & & 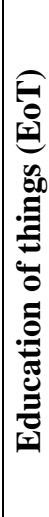 & 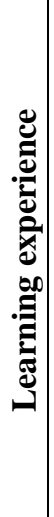 & 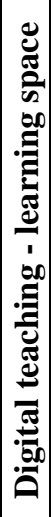 & : & 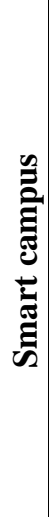 & 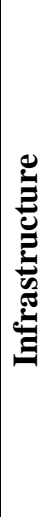 & 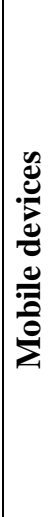 & 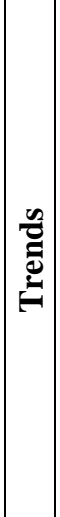 & 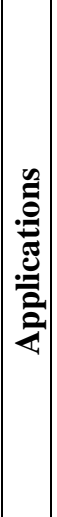 & 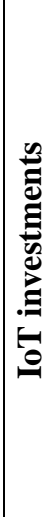 & 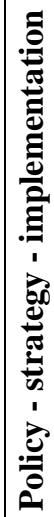 & 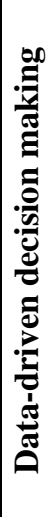 & 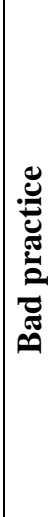 & | & ن̃ & 总 \\
\hline Ogallo (2018) & $\begin{array}{l}\text { IoT in HE , principles of IoT, data- } \\
\text { driven decision making in higher } \\
\text { education, HEI policy, campus } \\
\text { network, free flow of information, } \\
\text { institutional strategy, IoT HE } \\
\text { applications. }\end{array}$ & & & & & $\mathrm{X}$ & & & & $\mathrm{x}$ & & $\mathrm{x}$ & $x$ & & & & \\
\hline Tan (2018) & $\begin{array}{l}\text { IoT in HE, IoT bad practice in HE, } \\
\text { strategy of implementing IoT in } \\
\text { HE. }\end{array}$ & & & & & & & & & & & $\mathrm{x}$ & & $\mathrm{X}$ & & & \\
\hline Grama (2019) & $\begin{array}{l}\text { IoT security, privacy and } \\
\text { infrastructure in HE, IoT in } \\
\text { campus, IoT bad practice in HE. }\end{array}$ & & & & & $\mathrm{x}$ & $x$ & & & & & & & $\mathrm{x}$ & $\mathrm{x}$ & & \\
\hline Idnomic (2019) & $\begin{array}{l}\text { IoT in HE, IoT bad practice in HE, } \\
\text { IoT trends in HE. }\end{array}$ & & & & & & & & & & & & & $\mathrm{x}$ & & & \\
\hline Ramlowat (2019) & $\begin{array}{l}\text { IoT in HE, communication } \\
\text { everything-to-everything, IoT } \\
\text { trend. }\end{array}$ & & & & & & & & $x$ & & & & & & & $\mathrm{x}$ & \\
\hline Stone (2019) & $\begin{array}{l}\text { IoT in HE, smart campus, digitally } \\
\text { interconnected teaching - learning } \\
\text { space, competitive Colleges. }\end{array}$ & & & $\mathrm{x}$ & & $\mathrm{x}$ & & & & & & & & & & & $\mathrm{X}$ \\
\hline Wilkins (2019) & $\begin{array}{l}\text { IoT in HE, IoT bad practice in HE, } \\
\text { IoT's ID badges. }\end{array}$ & & & & $\mathrm{X}$ & & & & & & & & & $\mathrm{X}$ & & & \\
\hline Brooks (2020) & $\begin{array}{l}\text { IoT in HE, Mobile devices as key } \\
\text { technology to support HE. }\end{array}$ & & & & & & & $\mathrm{X}$ & & & & & & & & & \\
\hline \begin{tabular}{|l|} 
Jenzabar (2020) \\
\end{tabular} & $\begin{array}{l}\text { IoT in HE, data analysis tools, HEI } \\
\text { investment in IoT. }\end{array}$ & & & & & & & & & & $\mathrm{X}$ & & $\mathrm{X}$ & & & & \\
\hline Srivastava (2020) & $\begin{array}{l}\text { IoT in HE, IoT and learning } \\
\text { experience. }\end{array}$ & & $\mathrm{X}$ & & & & & & & & & & & & & & \\
\hline Nehru (2020) & $\begin{array}{l}\text { IoT in HE, Education of Things } \\
\text { (EoT), safety, security and privacy }\end{array}$ & $\mathrm{X}$ & & & & & & & & & & & & & X & & \\
\hline
\end{tabular}

The table shows that the main research areas are bad practice and smart campus, followed by policy, strategy, implementation, safety, security, privacy, data-driven decision making of the IoT, authors' discussion of EoT 


\section{Issues in Information Systems \\ Volume 21, Issue 2, pp. 75-84, 2020}

(education of things), learning experience, digital teaching, learning space, ID badges, infrastructure, mobile devices, trends, applications, investments, communication and competitiveness of IoT. The key findings of Table 2 can be summarized as: IoT can be useful for all HEI's area and decision making. Recognized research areas are also the answer to the RQ2: What are the key research areas of IoT in HE?

According to fifth (Smart campus) and thirteen (Bad practice) columns of areas in the Table 2, the majority of authors focused on IoT bad practice and IoT in smart campuses which proves, that operational and not technical aspects of HE are the main focus of IoT studies in HE. In other word, the primary focus of IoT research in HE is not technology but people, therefore students, professors, administration and management. The research findings thus strongly encourage the researchers to identify and clarify the operational, organizational, personal and social challenges of planning, implementing and using IoT in HE.

Table 3. Advantages and disadvantages of IoT in HE

\begin{tabular}{|c|c|}
\hline Advantages of IoT in $\mathrm{HE}$ & Disadvantages of IoT in $\mathrm{HE}$ \\
\hline \multicolumn{2}{|c|}{ Teaching } \\
\hline $\begin{array}{l}\text { - Higher performance degree of professors’ teaching } \\
\text { activities and teaching automation. } \\
\text { - Data Analytics for HE teaching control. } \\
\text { - Using Machine learning and Artificial intelligence to } \\
\text { support HE teaching. } \\
\text { - Discover hidden opportunities for better teaching. } \\
\text { - Innovative teaching. } \\
\text { - Managing study tours, excursions, etc. }\end{array}$ & $\begin{array}{l}\text { Excellent yet more traditional professors might not } \\
\text { want to teach in a total IoT environment. } \\
\text { - Focus on student activities not teaching quality. } \\
\text { - Lack of social interactions with students. } \\
\text { - Lack of real-life professors' influence on students. }\end{array}$ \\
\hline \multicolumn{2}{|c|}{ Learning } \\
\hline $\begin{array}{l}\text { - Higher performance degree of student learning } \\
\text { activities. } \\
\text { - Data Analytics for HE learning control. } \\
\text { - Learning automation. } \\
\text { - Using Machine learning and Artificial intelligence to } \\
\text { support HE learning. } \\
\text { - Discover hidden opportunities for better learning. } \\
\text { - Enhance the student learning experience. } \\
\text { - Promotion of experiential learning. } \\
\text { - Better student learning outcomes. }\end{array}$ & $\begin{array}{l}\text { - Less student privacy (personal data). } \\
\text { - Potential misinterpretation of student activities data. } \\
\text { - Lacking real social - live student learning } \\
\text { experiences. } \\
\text { - Some students prefer a more traditional environment. }\end{array}$ \\
\hline \multicolumn{2}{|c|}{ Students and professors logistics } \\
\hline $\begin{array}{l}\text { Face, voice and biometric detection and } \\
\text { recognition in classrooms, campuses and } \\
\text { especially during e-exams. } \\
\text { - Transportation devices and bike monitoring. } \\
\text { - Location tracking. }\end{array}$ & $\begin{array}{l}\text { Decreasing student motivation for non-education } \\
\text { activities as a result of total monitoring. } \\
\text { Total control of students' free time (detailed IoT } \\
\text { device monitoring). }\end{array}$ \\
\hline \multicolumn{2}{|c|}{ Supporting activities } \\
\hline $\begin{array}{l}\text { - Student activities monitoring anytime / anywhere. } \\
\text { - Enhancing Smart Campuses. } \\
\text { - IoT data can support students' and professors’ time } \\
\text { management and } \\
\text { - eStudent office. }\end{array}$ & $\begin{array}{l}\text { - An impact on professors' social interaction. } \\
\text { - Very high impact on students' life. } \\
\text { - Impact on long term students and professors } \\
\text { psychological behavior in a “non-hidden IoT” } \\
\text { environment. }\end{array}$ \\
\hline \multicolumn{2}{|c|}{ Infrastructure } \\
\hline $\begin{array}{l}\text { - Digitally interconnected learning spaces. } \\
\text { - IoT devices monitoring HEI infrastructure. } \\
\text { - Communication of everything to everything. } \\
\text { - Mobile to everything, everywhere, always. } \\
\text { - Electricity, heating and cooling management. } \\
\text { - Cantinas, vending machines: food \& beverages and } \\
\text { other supply chain management. }\end{array}$ & $\begin{array}{l}\text { Potential free flow of information across HEIs. } \\
\text { - Very high dependence on ICT and other technology } \\
\text { with technological and systems risk. } \\
\text { - High investments in infrastructure. }\end{array}$ \\
\hline
\end{tabular}


Table 3. Advantages and disadvantages of IoT in HE

\begin{tabular}{|c|c|}
\hline Advantages of IoT in HE & Disadvantages of IoT in HE \\
\hline \multicolumn{2}{|c|}{ HEIs management } \\
\hline $\begin{array}{l}\text { - Higher performance degree of HEIs processes. } \\
\text { - Sustained balance: HEI's efficiency / professors and } \\
\text { students privacy. } \\
\text { - Using Machine learning and Artificial intelligence to } \\
\text { support HEI management. } \\
\text { - Potentially reduce the costs of teaching. } \\
\text { - HEI’s increase in competitive advantage. } \\
\text { - Efficient HEI back office and management (e. g. } \\
\text { administration, invoicing, taxes, payments etc.). } \\
\text { - HEI Privacy and security management. }\end{array}$ & $\begin{array}{l}\text { HEI overall cybersecurity risk. } \\
\text { Increased costs for developing Machine learning and } \\
\text { AI applications to support HEI decision making. } \\
\text { IoT-controlled environment may be recognized as a } \\
\text { disadvantage to some professors and students. }\end{array}$ \\
\hline
\end{tabular}

The IoT influences HE in various ways. Literature review has mostly recognized advantages of IoT in HE. But the majority of authors also recognized several disadvantages. Thus the research focused on different advantages and disadvantages of the IoT, organized around the key IoT research areas of teaching, learning, student and professor logistics, supporting activities, infrastructure and HEI management as shown in Table 3: Advantages and disadvantages of IoT in HE. The research areas derived from Table 1: Studies on IoT and Table 2: Studies on IoT in HE keyword analysis and grouping. As listed in Table 3, according to authors there are more advantages than disadvantages.

Teaching activities deliver study activities and guide students learning activities. Among the IoT teaching advantages, we recognized a higher performance degree of professors teaching activities, supported by data analytics for HE teaching control. The IoT enables teaching automation, using machine learning and artificial intelligence algorithms. Moreover, the algorithms, using IoT-gathered big data, discover hidden opportunities for better and innovative teaching. The IoT environment supports guiding study tours and educational excursions. Authors also identified some teaching disadvantages, for instance that more traditional professors might not want to teach in a totally IoT environment, professors may focus on student activities more than on teaching quality, and last but not least, there is a lack of social interactions between professors and students. There is also a lack of real-life professors' influence on students resulting in less student social competencies.

Learning activities ensure that individual students acquire useful knowledge and competences. Among the IoT learning advantages authors recognized a higher degree of student learning activities, supported by data analytics for HE learning control. The IoT enables learning automation, using machine learning and artificial intelligence algorithms. The algorithms using IoT data discover hidden opportunities for better learning and enhance student learning experience, especially experiential learning, resulting in better student learning outcomes. Authors also listed several disadvantages, as less student privacy regarding students' personal and sensitive data, potential misinterpretations of student activities data, not focused on their learning activities. Students can expect less real social life and live student learning experiences. Some students may prefer a more traditional environment and recognize the IoT environment as too open but not enough connected with student real life.

Student and professor logistics activities support teaching and learning activities. Authors listed several IoT students and professors logistics advantages: face, voice and biometric detection and recognition in classrooms, campuses and e-classrooms and especially at e-exams, transportation devices and bikes monitoring, professors and students' location tracking. Authors also exposed some IoT disadvantages, for instance decreasing student motivation for non-education activities as a result of intensive IoT monitoring and total control of student free time - detailed IoT device monitoring.

Supporting activities improve professors' and students' overall living conditions, and increase their effectiveness. The most important IoT supporting activities advantage is based on student activities monitoring anytime / anywhere by IoT smart devices. There are many further advantages, e.g. enhancing smart campuses, IoT data can support students' and professors' time management and improve the so-called eStudent office. There are also some disadvantages, such as the IoT impact on professors-to-student interactions and overall student life. Impact on long term students' and professors' psychological behavior in a "non-hidden IoT" environment is also recognized.

IoT infrastructure ensures an effective and safe environment of connected smart devices to support HEI's processes. The main advantage is digitally interconnected learning spaces. Cloud-based IoT platforms provide 
comprehensive IoT devices monitoring of HEI's infrastructure, communication of everything to everything, mobile to everything, everywhere and always and electricity, heating and cooling management. IoT infrastructure contributes to everyday professors and students comfortable and well-organized life in cantinas, vending machines: food \& beverages and other supply chain management. There are also some disadvantages, like potential free flow of information across HEIs, very high dependence on IT and other technology with technological and systems risk and high investments in IoT infrastructure.

HEI management is responsible for smooth and successful HEI development and performance. The IoT provides some real advantages to increase the performance of HEI's processes with a sustained balance of HEI efficiency vs. professors' and students' privacy. Using machine learning and artificial intelligence algorithms supports overall management processes, potentially reduces costs of teaching and increases HEI's competitive advantage on highly competitive HE markets. IoT also contributes to efficient back-office and management (e.g. administration, invoicing, taxes, payments, etc.) and to privacy and security management. There are also some management disadvantages like overall cybersecurity and system risk, increased costs for developing machine learning and artificial intelligence applications to support HEI decision-making.

Recognized, described and illustrated advantages and disadvantages of the IoT in HE are also the answer to the RQ3: What are the key advantages and disadvantages of IoT in HE?

\section{CONCLUSION}

Several authors researched the IoT in different areas, including HE. The student-oriented HE is traditionally focused on face-to-face or online teaching and learning. The device-based IoT platforms in $\mathrm{HE}$ are still in an initial stage but internet-connected devices represent an important difference to new generations of "digital native students" and even more for professors belonging to previous generations, who are mainly non-digital natives.

The research firstly focuses on IoT studies to seek the answer to the RQ1: What are the key research areas of IoT? The main research areas of the IoT can be summarized as IoT technical issues and corresponding platforms, followed by industrial IoT, social issues and safety, security and privacy issues of IoT and authors' discussion of IoT trends.

The research also focuses on IoT studies in HE as to seek the answer to the RQ2: What are the key research areas of IoT in HE? The main research areas of the IoT in HE are bad practice and smart campus followed by policy, strategy, implementation, safety, security, privacy, data-driven decision making of IoT, authors discussing the EoT (education of things), learning experience, digital teaching, learning space, ID badges, infrastructure, mobile devices, trends, applications, investments, communication and competitiveness of the IoT. The research also discovers that the IoT can be useful for all HEI areas and decision making as a key finding of this research phase.

In the final part, the research focuses on advantages and disadvantages of the IoT in HE, seeking the answer to the RQ3: What are the key advantages and disadvantages of IoT in HE? The research pointed out that the IoT has various influences in/on HE and recognized main advantages and disadvantages of IoT in HE, organized around the key IoT research areas of teaching, learning, student and professor logistics, supporting activities, infrastructure and HEI management. The research discovers more advantages than disadvantages of IoT in HE.

The main potential of the IoT is personalization of HE processes to support students, teachers, administration/management individuals' characteristics to improve the efficiency of teaching, learning and HEI management. The recognition of main IoT research areas, advantages and disadvantages promote the HEI identification of key future challenges to improve overall data-driven decision-making in HE.

The research was mainly limited to literature reviews and focused comprehensive analyses and comparison of advantages and disadvantages of IoT in higher education from various perspectives. The future research should include an empirical survey focusing on whether the defined areas of the IoT and the IoT in HE are representative enough and potentially identifying the missing or related areas. The future research should also discover the key differences of advantages and disadvantages among main stakeholders in the teaching and learning process professors, administration, HEI management, belonging to different but mostly older generations and digital native student generation. 


\section{REFERENCES}

Al-Emran, M., Malik, S.I. \& Al-Kabi, M.N. (2020). A Survey of Internet of Things (IoT) in Education: Opportunities and Challenges. In: Hassanien, A., Bhatnagar, R., Khalifa N. \& Taha M. (eds) Toward Social Internet of Things (SIoT): Enabling Technologies, Architectures and Applications. Studies in Computational Intelligence, vol 846. Springer, Cham.

Brooks, D. C., McCormack, M. \& Shulman, B. (2020). EDUCAUSE Center for Analysis and Research ECAR. https://library.educause.edu/resources/2020/1/higher-educations-2020-trend-watch-and-top-10strategic-technologies.

Grama, J.L. \& Milford, K. (2019). Ahead of the Curve: IoT Security, Privacy, and Policy in Higher Ed. In: Hudson F. (eds) Women Securing the Future with TIPPSS for IoT. Women in Engineering and Science. Springer, Cham.

Idnomic. 2019. https://www.idnomic.com/en/the-five-iot-trends-of-2019/

Jenzabar. (2020). Higher education Technology Trends to Watch in 2020. https://www.jenzabar.com/blog/higher-education-technology-trends-to-watch-in-2020

Laudon, K.C. \& Laudon, J.P. (2016). Management information Systems, Managing the digital firm. 14.ed. Global ed. Pearson.

Moreira, F., Ferreira, M.J. \& Cardoso, A. (2017). Higher Education Disruption Through IoT and Big Data: A Conceptual Approach. In: Zaphiris, P. \& Ioannou, A. (eds) Learning and Collaboration Technologies. Novel Learning Ecosystems. LCT 2017. Lecture Notes in Computer Science, vol 10295. Springer, Cham

Nehru, R.S.S. \& Chakraborty, S. (2020). The Education of Things (EoT) for Smart Learning Through IoT Intervention: A Case Study Based Analysis. In: Gunjan, V., Garcia Diaz, V., Cardona, M., Solanki, V. \& Sunitha, K. (eds) ICICCT 2019 - System Reliability, Quality Control, Safety, Maintenance and Management. ICICCT 2019. Springer, Singapore.

Ogallo, G.G. (2018). IoT - Enhancing Data-driven Decision-making in Higher Education. Case Study of Ohio University. Published by ProQuest LLC

Ramlowat, D.D. \& Pattanayak, B.K. (2019). Exploring the Internet of Things (IoT) in Education: A Review. In: Satapathy, S., Bhateja, V., Somanah, R., Yang, X.S. \& Senkerik, R. (eds) Information Systems Design and Intelligent Applications. Advances in Intelligent Systems and Computing, vol 863. Springer, Singapore.

Ravulavaru, A. (2018). Enterprise Internet of Things Handbook. Packt Publishing. 2018.

Rossman, J. (2016). The Amazon Way on IoT. Clyde Hill Publishing.

Sibo, W. (2017). The General Development Trends of IoT. CAICT Industry and Planning Research Institute.

Srivastava, M., Saurabh, P. \& Verma, B. (2020). IOT for Capturing Information and Providing Assessment Framework for Higher Educational Institutions-A Framework for Future Learning. In: Das K., Bansal J., Deep K., Nagar A., Pathipooranam P., Naidu R. (eds) Soft Computing for Problem Solving. Advances in Intelligent Systems and Computing, vol 1057. Springer, Singapore.

Stone, A. (2019). AI and Smart Campuses are among Higher Ed Tech to watch in 2020. https://edtechmagazine.com/higher/article/2019/12/ai-and-smart-campuses-are-among-higher-ed-techwatch-2020-1 
Issues in Information Systems

Volume 21, Issue 2, pp. 75-84, 2020

Tan, P., Wu, H., Li, P., \& Xu, H. (2018). Teaching management system with applications of RFID and IoT technology. Education Sciences, 8(1), 26. doi:http://dx.doi.org/10.3390/educsci8010026

Wilkins, N. (2019). Internet of Things. Amazon Fulfillment. 